\title{
FLORA DE GRÃO-MOGOL, MINAS GERAIS: RHAMNACEAE ${ }^{1}$
}

\author{
RITA BALTAZAR LIMA \\ Departamento de Sistemática e Ecologia, CCEN, Universidade Federal da Paraíba, \\ Caixa Postal 5065, 58051-970 - João Pessoa, PB, Brasil.
}

\begin{abstract}
Johnston, M.C. \& Soares, M.A.F. 1972. Rhamnáceas. In R. Reitz (ed.) Flora ilustrada Catarinense. Herbário Barbosa Rodrigues. Itajaí.

Lima, R.L. \& Giulietti, A.M. 2005. Rhamnaceae. In M.G.L. Wanderley, G.J. Shepherd, T.S. Melhem, S.E. Martins, M. Kirizawa \& A.M. Giulietti (eds.) Flora fanerogâmica do Estado de São Paulo. FAPESP, RiMa. São Paulo, vol. 4, p. 331-341.

ReIssek, S. 1861. Rhamneae. In C.F.P. Martius \& A.G. Eichler (eds.) Flora brasiliensis. Frid. Fleischer. Leipzig, vol. 11, pars 1, p. 81-116.

Suessenguth, K. 1953. Rhamnaceae. In A. Engler \& K. Prantl (eds.) Die natürlichen Pflanzenfamilien. Duncker \& Humblot. Berlin, vol. 20d, p. 1-173.

1. Arbustos ou arvoretas; ovário súpero; fruto drupa Rhamnus sphaerosperma

1'. Lianas com gavinhas; ovário ínfero; fruto esquizocarpo com mericarpos alados Gouania latifolia
\end{abstract}

\section{Gouania Jacq.}

Lianas sarmentosas, gavinhas laxas ou circinadas. Folhas alternas, pecioladas, lâmina cordiforme a elíptica, margem inteira, serreada ou denteada, com glândulas conspícuas, nervação actinódroma; estípulas laterais, lanceoladas, inteiras ou lobadas. Inflorescência em fascículos dispostos ao longo de raque axilar ou terminal. Flores bissexuadas e masculinas na mesma inflorescência; 5-meras, actinomorfas, epíginas; hipanto obcônico; sépalas valvares, patentes ou eretas; pétalas livres, ungüiculadas, convolutas ou cuculadas; disco nectarífero membranáceo, lobado na margem distal, glabro ou pubescente a velutino; estames 5, opostos às pétalas, anteras bitecas; ovário ínfero, 3-carpelar, 3-locular, estiletes 3; óvulo 1 por lóculo, basal. Fruto esquizocarpo; mericarpos 3, alados, cartáceos, glabros a velutinos, unisseminados.

1.1. Gouania latifolia Reissek in Mart., Fl. bras. 11(1): 103. 1861.

Liana com ramos estriados, velutinos; gavinhas delgadas, circinadas apenas no ápice. Folhas cartáceas, pecíolo $0,5-1,5 \mathrm{~cm}$ compr.; lâmina $5-8 \mathrm{~cm}$ compr., 3,5-6,5 cm larg., cordiforme ou ovalada, ápice agudo, base cordada, margem serreada a denteada, velutina em ambas faces, nervuras laterais 6-8. Flores bissexuadas ca. $3 \mathrm{~mm}$, subsésseis; pétalas ca. $1 \mathrm{~mm}$ compr., creme; estames $0,8-1 \mathrm{~mm}$ compr., anteras suborbiculares; disco nectarífero velutino; estiletes $0,8-1 \mathrm{~mm}$ compr., unidos até a metade, glabros; estilódios nas flores masculinas $0,3 \mathrm{~mm}$. Esquizocarpo 7$8 \mathrm{~mm}$ compr., velutino; pedicelo 1-1,5 mm compr., alas do mericarpo reduzidas, 2-3,5 mm larg.; sementes 3-4 mm compr., elípticas. (Fig. 1 A-E).

Pirani et al. CFCR 879 (NY, SP, SPF).

Material complementar: Minas Gerais, Araponga, 4.IV.1986, Vieira et al. 352 (UEC); Belo Horizonte, 20.IV.1995, J.A. Lombardi \& L.G. Temponi 749 (BHCB). Rio de Janeiro: Petrópolis, 20.VII.1978, J.P. Carauta \& Magnanini 2992 (RB, SPF). São Paulo: Analândia, III.1995, M.A. Assis et al. 484 (HRCB, UEC); Campinas, 4.IV.1994, Carmo et al.

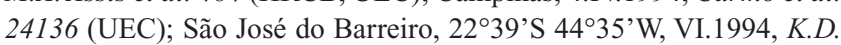
Barreto et al. 2643 (ESA).

Espécie distribuída no Centro-Oeste, Sudeste e Sul do Brasil. Em Grão-Mogol foi coletada na orla de mata ciliar, com flores em abril.

${ }^{1}$ Trabalho realizado conforme o planejamento apresentado por Pirani et al. (2003). Bol. Bot. Univ. São Paulo 21(1): 1-24. 


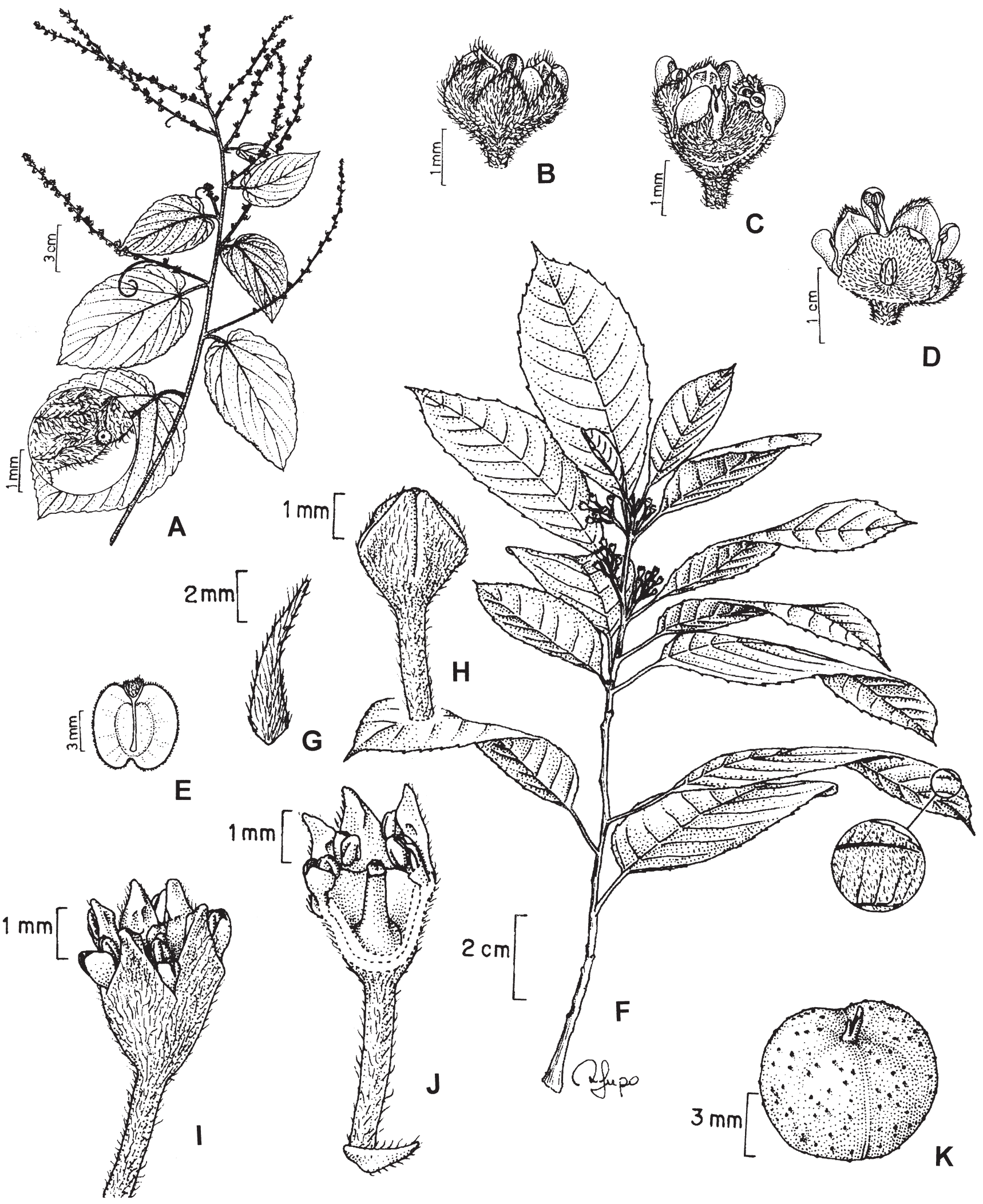

Fig.1. RHAMNACEAE. A-E. Gouania latifolia: A. Ramo com flores, B. Flor bissexuada; C. Flor bissexuada em cote longitudinal; D. Flor masculina, corte longitudinal, vista subfrontal; E. Mericarpo. F-K. Rhamnus sphaerosperma: F. Ramo com flores; G. Estípula; H. Botão floral; I. Flor na antese; J. Flor em corte longitudinal; K. Fruto drupa (A-D, Carmo et al. 24136; E, Carauta \& Magnanini 2992; F-K. Lima \& Melo 1626). 


\section{Rhamnus L.}

Árvores ou arbustos, inermes ou espinescentes. Folhas alternas, pecioladas, lâmina ovalada a elíptica, margem serreada, sem glândulas, nervação eucamptódroma; estípulas laterais, precocemente decíduas. Inflorescência em tirso congesto axilar. Flores bissexuadas, 5-meras, actinomorfas, períginas; hipanto obcônico; sépalas valvares, eretas; pétalas livres, ungüiculadas, cuculadas; disco nectarífero membranáceo, não-lobado, glabro; estames 5 , opostos às pétalas, anteras bitecas; ovário súpero, 3-carpelar, 3-locular, estiletes 3; unidos; óvulo 1 por lóculo, basal. Fruto drupa, pirenos 3, glabros, unisseminados.

2.1. Rhamnus sphaerosperma Sw., Prod. Veg. Ind. Occ.: 50. 1788 .

Arbusto ou arvoreta 2,5-4 m alt. Folhas cartáceas, pecíolo 1-1,5 cm compr.; lâmina 5-9 cm compr., 2,3-3,8 cm larg., elíptica, ápice acuminado, base aguda, margem finamente serreada e revoluta, pubérula na face adaxial e pubescente ou velutina na face abaxial, nervuras laterais 5-7 pares; estípulas subuladas. Flores ca. $5 \mathrm{~mm}$, ligeiramente campanuladas, pediceladas; pétalas ca. 1,3 mm compr., creme, ápice bilobado; estames ca. 1,4 mm compr., anteras levemente rostradas, muitas vezes com tecas desiguais; estilete 1,5-1,9 $\mathrm{mm}$ compr., sulcado longitudinalmente. Drupa 1,2-1,5 mm compr., glabra; pedicelo 6-7 mm compr., sementes ca. 4,3 mm compr., suborbiculares. (Fig. 1 F-K).
Harley et al. CFCR 6520 (BHCB, CTES, K, MBM, SP, SPF); Pirani et al. CFCR 11507 (IBGE, IPA, MO, RB, SP, SPF, US); Sano et al. CFCR 12440 (CEPEC, F, G, ICN, NY, SPF, UB).

Material complementar: Minas Gerais, Diamantina, 14.XI.1971, G. Hatschbach 27946 (MBM. TEX); Serra do Espinhaço, 13.II.1972, W. Anderson et al. 35923 (UB).

Espécie distribuída do sul do México e Caribe até a Argentina, com 4 variedades segundo Johnston \& Johnston (1978). Em Grão-Mogol está representada por R. sphaerosperma var. pubescens (Reissek) M.C. Johnst., cuja distribuição vai do Nordeste (Bahia) ao Sudeste e Sul do Brasil, ocorrendo em cerrado, matas ciliares e matas montanas. Em Grão-Mogol aparece como heliófita na orla de mata ciliar e mesmo entre grandes rochas no campo rupestre. Foi coletada com flores e frutos em novembro e dezembro. 
